\title{
Fibre-optic monitoring for high-temperature Carbon Capture, Utilisation and Storage (CCUS) projects at geothermal energy sites
}

\author{
Anna L. Stork ${ }^{1}$, Athena Chalari ${ }^{1}$, Sevket Durucan ${ }^{2}$, Anna Korre ${ }^{2}$, Stoyan Nikolov ${ }^{1}$ \\ 1. Silixa Limited, 230 Centennial Avenue, Centennial, Elstree, Herts. WD6 3SN, United Kingdom \\ 2. Department of Earth Science and Engineering, Royal School of Mines, Imperial College \\ London, London SW7 2AZ, United Kingdom
}

\begin{abstract}
It is often assumed that geothermal energy provides a clean source of renewable energy without emissions of carbon dioxide $\left(\mathrm{CO}_{2}\right)$ or other greenhouse gases. In fact, most geothermal energy plants emit $\mathrm{CO}_{2}$ and small amounts of other gases, typically up to $5 \%$ of by weight. Reinjection of produced $\mathrm{CO}_{2}$ back into the geothermal fields has been proposed by several researchers in the past. The EU funded CarbFix and CarbFix2 projects have successfully demonstrated that $\mathrm{CO}_{2}$ reinjection into basaltic rocks can provide a safe and efficient geological storage method. The ACT Programme funded SUCCEED project is focused on understanding the effects of and developing technologies to enable reinjection of produced $\mathrm{CO}_{2}$ at geothermal plants in different geological settings. Monitoring the process is vital to understand the effects, possibilities and limitations of injection but the availability of suitable sensors is limited in high-temperature and harsh environments. This problem can be overcome with the use of distributed fibre-optic sensors which are able to withstand such harsh environments and record temperature, seismic and strain signals. This article describes actual and planned deployments of Distributed Acoustic Sensing (DAS) technology at the Hellisheidi and Kizildere geothermal fields in Iceland and Turkey, respectively, and outlines the practical considerations for such deployments.
\end{abstract}

\section{Introduction}

The transition to renewable energies requires adaptation of existing technologies and the development of new techniques. The geothermal energy industry is currently small globally but provides a significant proportion of the energy requirements in some countries, for example Iceland and Philippines. This industry is considered a "green" and renewable source of energy that can help combat anthropogenic climate change. Actually, most geothermal plants emit some carbon dioxide $\left(\mathrm{CO}_{2}\right)$ and other greenhouse gases, with, on average, about $5 \%$ of the $\mathrm{CO}_{2}$ emitted by coal-fired plants of equal size (Holm et al., 2012). With significant potential for geothermal energy identified in countries such as Indonesia, Ethiopia, and Turkey, it is important that the industry is developed in a sustainable way, minimising emissions.

Due to the high geothermal fluid-flow rate requirement of power plants, non-condensable gases, such as $\mathrm{CO}_{2}$, that are produced alongside the geothermal fluids are normally vented to the atmosphere. The produced fluid, depleted in $\mathrm{CO}_{2}$, is generally re-injected into the reservoir. Consequently, the geothermal fluid resource in the reservoir is gradually diluted and the field pressure reduces over time, affecting well productivity. Reinjection of produced $\mathrm{CO}_{2}$ into geothermal fields has been proposed by several researchers (e.g., Pruess, 2006; Salimi and Wolf, 2012). The EU funded CarbFix and CarbFix2 projects aimed to evaluate the performance of $\mathrm{CO}_{2}$ injection into basaltic rocks at the Hellisheidi geothermal field in Iceland. The process is similar in concept to enhanced oil recovery (EOR) with $\mathrm{CO}_{2}$ where the $\mathrm{CO}_{2}$ is injected to enhance production while storing the $\mathrm{CO}_{2}$ underground. In EOR projects the $\mathrm{CO}_{2}$ is stored in depleted oil and gas reservoirs whereas storage of $\mathrm{CO}_{2}$ at geothermal sites may involve storage in volcanic rocks or fractured reservoirs. The CarbFix projects evaluated safety aspects 
and long-term storage through mineralisation (McGrail et al., 2006). Modelling and field geochemical monitoring results for basaltic rocks suggested that complete mineralisation of injected $\mathrm{CO}_{2}$ takes less than two years (Snæbjörnsdóttir et al., 2017).

A similar scheme to the CarbFix technology was developed at the Umurlu geothermal field near Aydin, Turkey and produced non-condensable gas was injected into the reservoir for 20 days, at an average rate of 2.65 tonnes/hour (Yucetas et al., 2018). $\mathrm{CO}_{2}$ content measurements taken from the reservoir fluid samples in observation wells showed noticeable increase in the $\mathrm{CO}_{2}$ content, suggesting that this technology could be effective in re-saturating the reservoir. Therefore, it is believed that injection of supercritical $\mathrm{CO}_{2}$ into geothermal reservoirs can enhance reservoir pressure as the driving mechanism for the geothermal fluid and improve geothermal performance.

The monitoring efforts described here focus on understanding the effects of and developing technologies to enable reinjection of produced $\mathrm{CO}_{2}$ at geothermal plants in different geological settings as part of the ACT Programme (Accelerating CCS Technologies) funded SUCCEED project. The Hellisheidi geothermal field in Iceland is one of the study sites and the second is the Kizildere geothermal field in Turkey with a fractured carbonate reservoir. To date the only European pilot study to investigate monitoring of permanent storage of $\mathrm{CO}_{2}$ in a carbonate system has been the Hontomin project in Spain (Humphries et al., 2016), not a geothermal site.

We outline the testing and development of geophysical monitoring technologies and techniques for combined geothermal and carbon capture and storage (CCS) sites. Geothermal reservoirs present unique monitoring and characterisation challenges with harsh, high temperature downhole environments. The combination of geothermal energy production with CCS presents further challenges because the injection of $\mathrm{CO}_{2}$ must be monitored to understand the migration of the $\mathrm{CO}_{2}$ and verify that the $\mathrm{CO}_{2}$ does not leak from the storage site. The sites are often higher temperature than the specification of standard instruments and therefore specialised equipment is required. Distributed fibre-optic sensing cables have been demonstrated to be suitably robust for extended duration installations in geothermal fields (e.g., Mondanos and Coleman, 2019), making them ideal to test and assess monitoring techniques at the Hellisheidi and Kizildere geothermal fields.

\section{Distributed Acoustic Sensing (DAS) technology}

The technology for fibre-optic sensing of acoustic and seismic wavefields has developed significantly in recent years and it is now often applied to monitor seismicity in industrial projects (e.g., Richter et al., 2019; Karrenbach et al., 2019). The technique is known as Distributed Acoustic Sensing (DAS) and it makes use of optical time domain reflectometry (OTDR) principles to detect seismic waves incident on a fibre-optic cable. DAS is based on digital optical detection of elastic Rayleigh backscattered light resulting from inhomogeneous variations of refractive index along a fibre. A DAS system can record the full wavefield amplitude and phase at every point along the fibre over a wide frequency and dynamic range. Changes in strain on the fibre due to the passage of seismic wavefronts result in changes in the recorded signal and interrogators (e.g., Figure 1) are able to measure changes in axial strain down to sub-nanostrain resolution (Parker et al., 2014). 


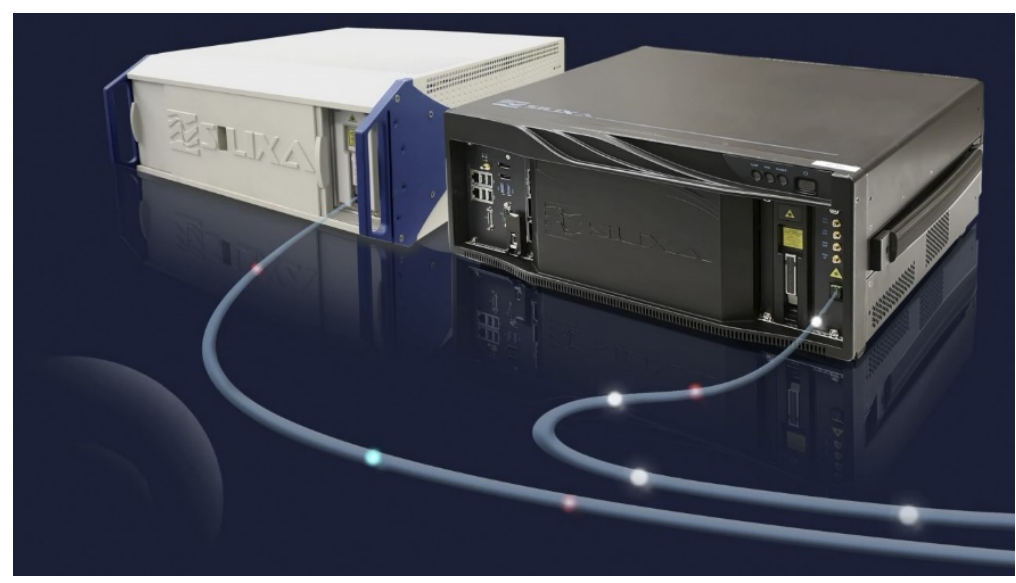

FIGURE 1: Silixa's intelligent Distributed Acoustic Sensing (iDAS) interrogators. On the left is the iDAS v2 and on the right the iDAS v3 (Carina) interrogator. Light is emitted from the interrogator and the back scattered light from the fibre is recorded.

The monitoring technology provides flexibility because it offers dense spatial and temporal sampling, less than $1 \mathrm{~m}$ and up to $100 \mathrm{kHz}$, respectively. Measurements can be made on a single cable up to tens of $\mathrm{km}$ long and recent advances in cable and interrogator technology have improved the signal-tonoise performance by $20 \mathrm{~dB}$ (100 times increase in power) with the availability of Silixa's Carina Sensing System (Naldrett et al., 2020). The Carina system uses specially engineered (Constellation) fibre to enhance the backscatter properties of the fibre and in settings with low expected signal-to-noise ratios it can therefore significantly improve the results of both passive and active seismic surveys.

Fibre-optic cables can be installed trenched at the surface, deployed into existing boreholes, or cemented behind casing in permanent installations to provide enhanced coupling. Once deployed the fibre provides a long-term and repeatable monitoring solution because the fibre can be left in place and data collected for up to tens of years. Another advantage of fibre-optic technology over traditional seismic instruments (geophones) is that cables with polyimide coatings enable DAS measurements in high-temperatures up to $300^{\circ} \mathrm{C}$, as often experienced in geothermal environments.

Geophones provide three-component recordings whereas DAS measurements are only onecomponent because fibres are only sensitive to axial strain, in the fibre direction. Thus, linear fibres are insensitive to seismic P-waves arriving broadside to the cable and the use of linear surface cables for active or passive seismic surveys, where the P-waves arrive nearly vertically, is limited. To address this issue helically wound cables (HWC) have been developed which boost the P-wave sensitivity, although they decrease S-wave sensitivity. The sensitivity is significantly affected by the wrapping angle (Baird, 2020) and often a $60^{\circ}$ wrapping angle is used to maximise the potential for recording both P- and S-waves.

\section{Combined geothermal and CCS field sites}

The Hellisheidi geothermal field (Figure 2) lies within the Hengill volcanic system of Iceland's western volcanic zone which has been studied extensively for the purposes of geothermal production (Snæbjörnsdóttir et al., 2018). The Hellisheidi combined heat and power plant began operations in 2006 , operated by Reykjavik Energy. The production capacity is $303 \mathrm{MWe}$ and 133MWth energy and the temperature of the field varies between $260^{\circ} \mathrm{C}$ and $320^{\circ} \mathrm{C}$ (Gunnarsson et al., 2013). Produced $\mathrm{CO}_{2}$ is reinjected at about $700 \mathrm{~m}$ depth into the, primarily basaltic, rocks of the volcanic system. Currently 
the site produces approximately 4,500 tonnes/hr of geothermal fluid, of which 3,800 tonnes/hour is reinjected into the reservoir via 17 wells. Annually around 12,000 tonnes of captured $\mathrm{CO}_{2}$ is also injected dissolved in water back into the geothermal reservoir.

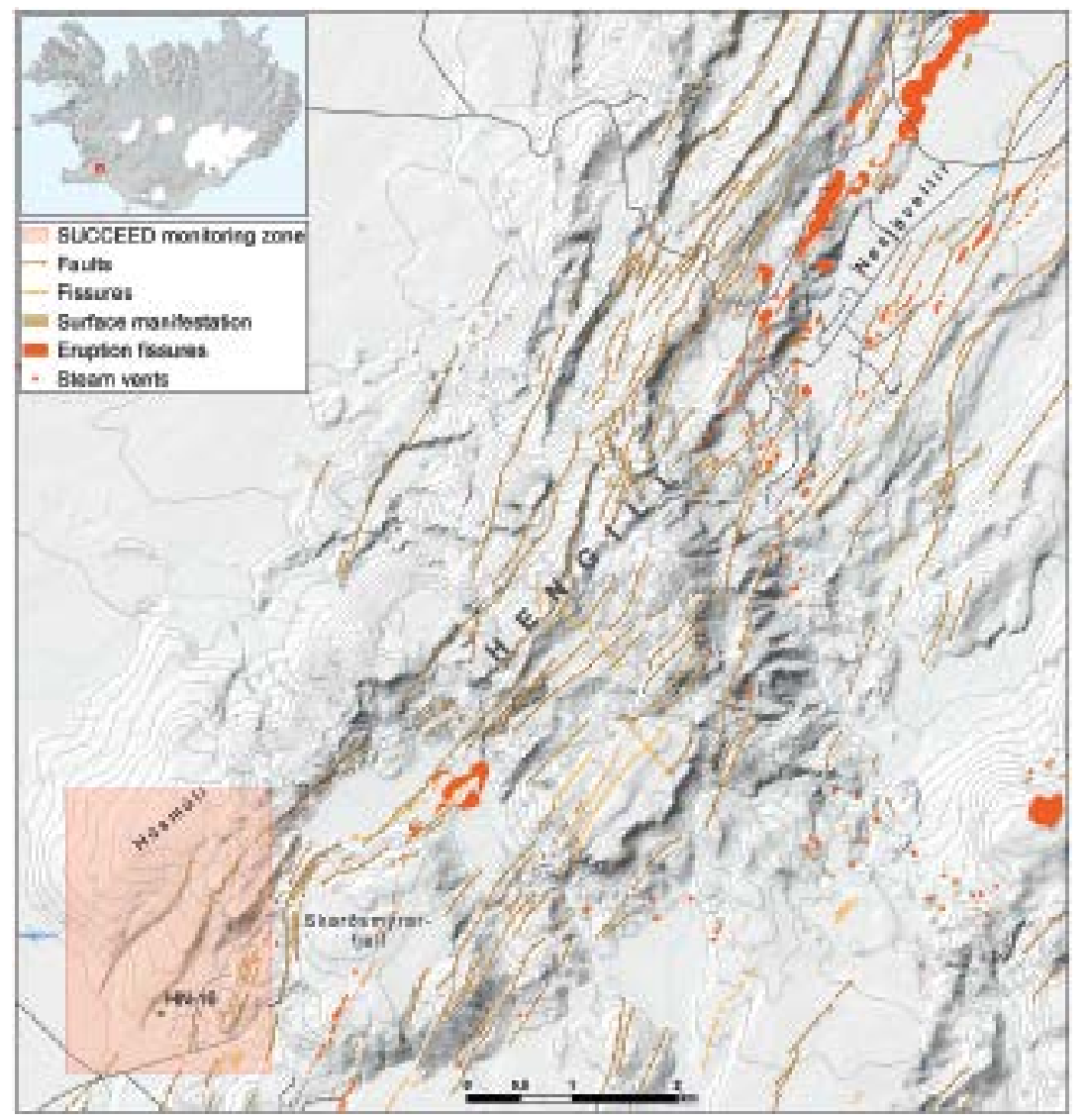

(a)

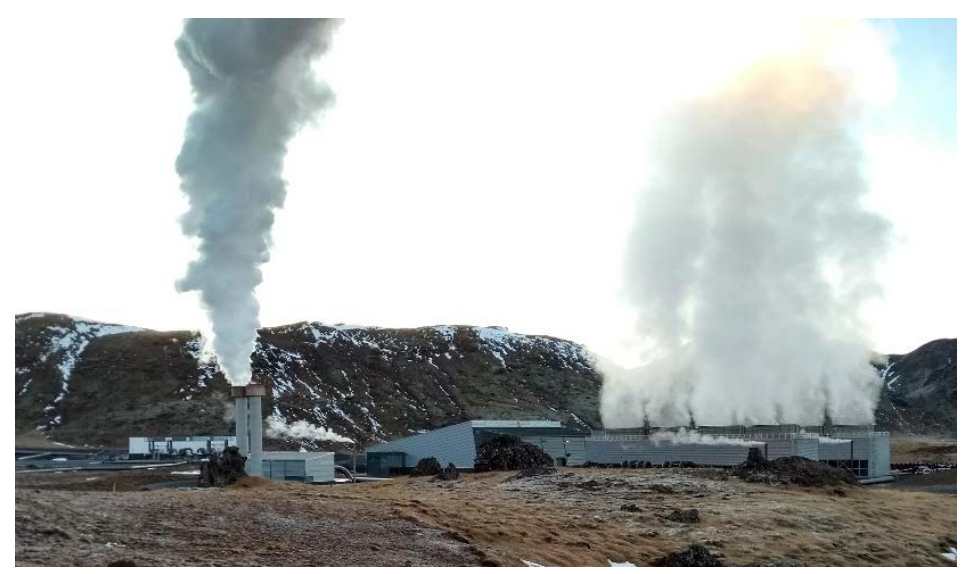

(b)

FIGURE 2: (a) The Hengill volcanic system and the SUCCEED seismic monitoring zone around the HN$16 \mathrm{CO} 2$ injection well at the Hellisheidi site marked with a red rectangle (Courtesy of T.A. Thorgeirsson, 2020), (b) the Hellisheidi geothermal power plant by Reykjavik Energy. 
In contrast to the volcanic environment in Iceland, the Kizildere geothermal plant, Turkey (Figure 3) produces from a carbonate hydrothermal reservoir. Due to the highly fractured nature of the system, fluid migration in the reservoir is considerably faster than it is in volcanic environments, which aids the observation and evaluation of changes in the reservoir over relatively short timescale. Production at the Kizildere site began in 1984 and reinjection of produced fluids commenced in 2002 with the aim of maintaining the reservoir pressure. Since then the concentration of dissolved $\mathrm{CO}_{2}$ in the reservoir fluids has decreased. Therefore, it is proposed to use an existing well at the geothermal power generation site to investigate the feasibility of injecting produced and captured $\mathrm{CO}_{2}$ into the reservoir as a supercritical fluid. If successful, this will result in a low environmental impact and resourceefficient coupled geothermal-CCUS power plant. Understanding the interaction between the injected fluid and the reservoir is vital to establish the long term operational and economic viability of $\mathrm{CO}_{2}$ injection at this site. Monitoring is required to investigate the extent to which the reservoir rocks are geochemically altered by the injection and the geomechanical implications of this for stability of operations. The high temperatures (up to $245^{\circ} \mathrm{C}$ ) in the geothermal reservoir poses a challenge for monitoring that can be overcome with the use of specially designed fibre-optic cables.

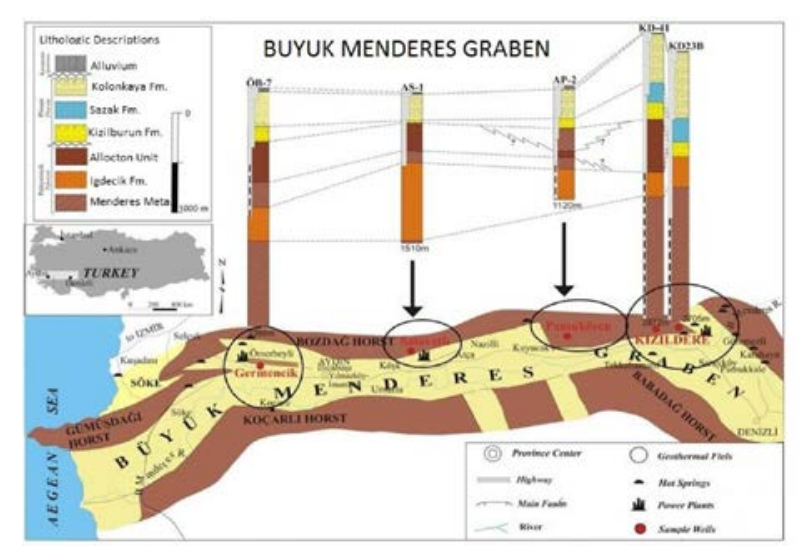

(a)

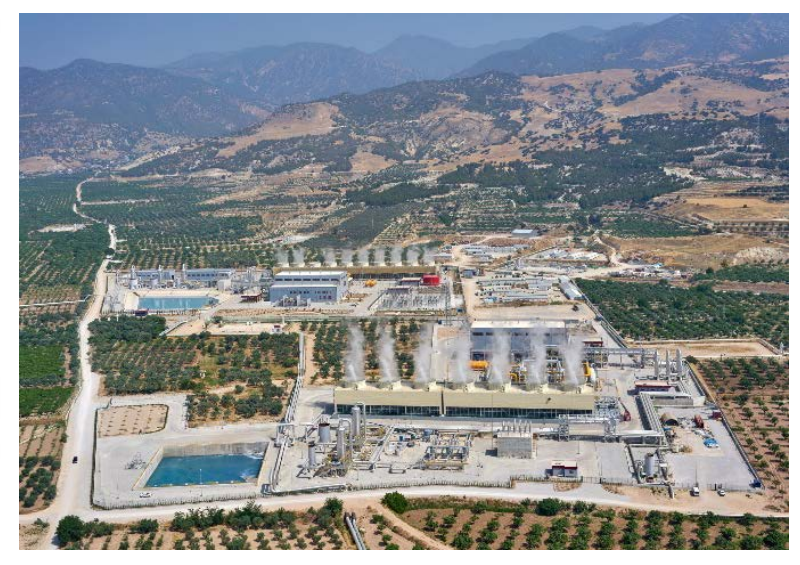

(b)

FIGURE 3: (a) Location of Kizildere geothermal field in Büyük Menderes Graben (Courtesy of Ş Şimsek, 2020), (b) the Zorlu Enerji Kızıldere-III geothermal power plant (Courtesy Zorlu Energy, 2020).

\section{Fibre-optic survey design}

A fibre-optic cable deployment has been carried out at the Hellisheidi field and is planned for the Kizildere site, where a baseline survey will be conducted before the injection of $\mathrm{CO}_{2}$ begins. The overall monitoring aim is to image and understand the behaviour of $\mathrm{CO}_{2}$ in the reservoir. The objectives for the fibre-optic surveys are:

1. Investigate the capabilities of HWC for microseismic monitoring and active seismic surveys;

2. Compare the performance of surface HWC and Constellation fibres in monitoring wells.

The ultimate objective is to determine suitable combinations of fibre-optic cables and interrogators for surface and borehole deployment for passive and active surveys in high-temperature environments. The deployments at both sites provide the possibility for continuous and repeatable time-lapse seismic monitoring capability with permanently installed cables. 
Since 2018, natural and induced seismicity has been recorded in the Hellisheidi area on a densified local seismometer network (Obermann et al., 2020). To understand and compare the capabilities of surface $\mathrm{HWC}$ for $\mathrm{CO}_{2}$ injection monitoring, a $1.5 \mathrm{~km}$ long cable is deployed in a trench and buried 70$80 \mathrm{~cm}$ deep (Figure 4). The cable is deployed on the surface as close as possible to the injection point of the $\mathrm{CO}_{2}$ injection well (Figure 4a). Data will be recorded continuously along with active surveys planned at the site.
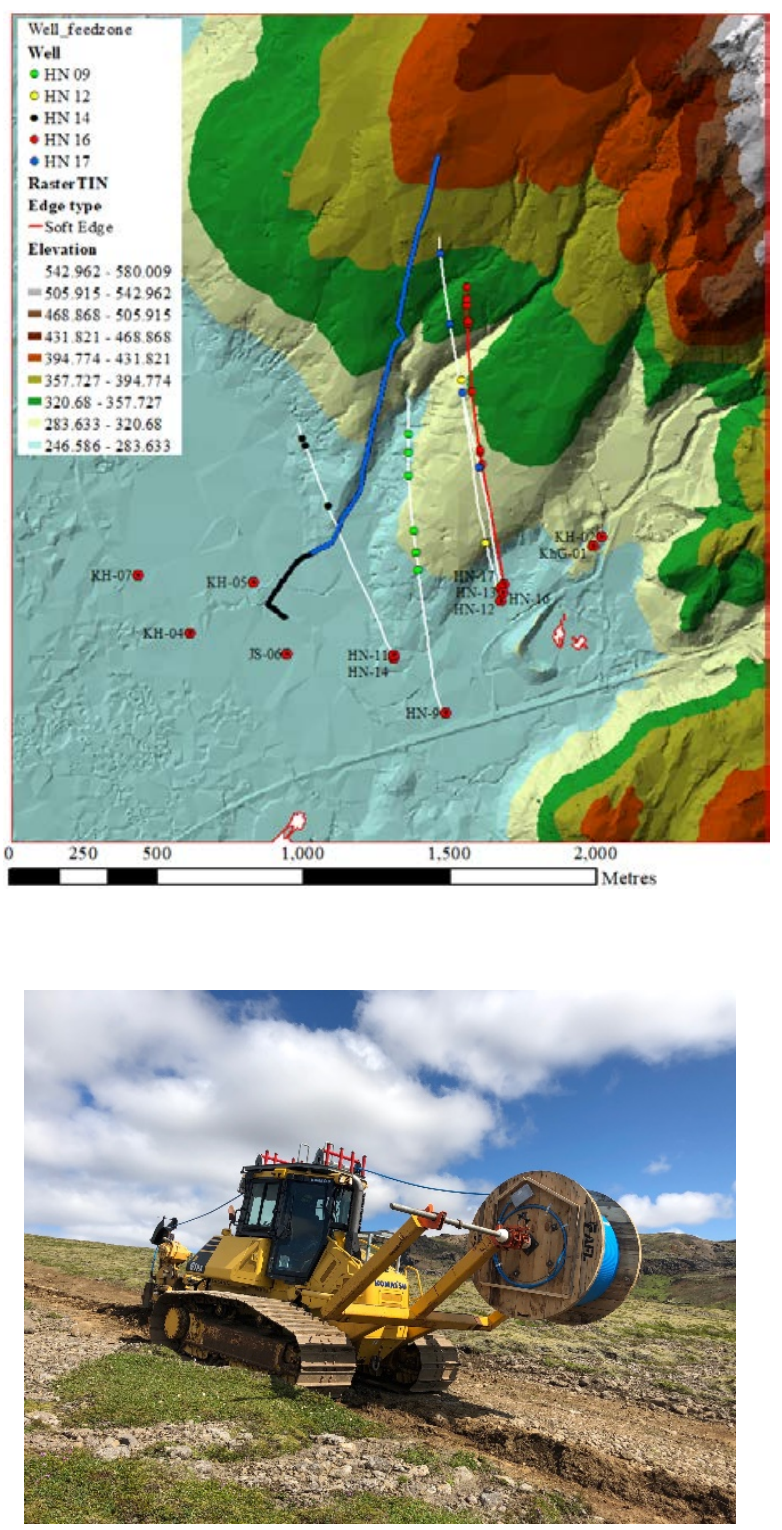

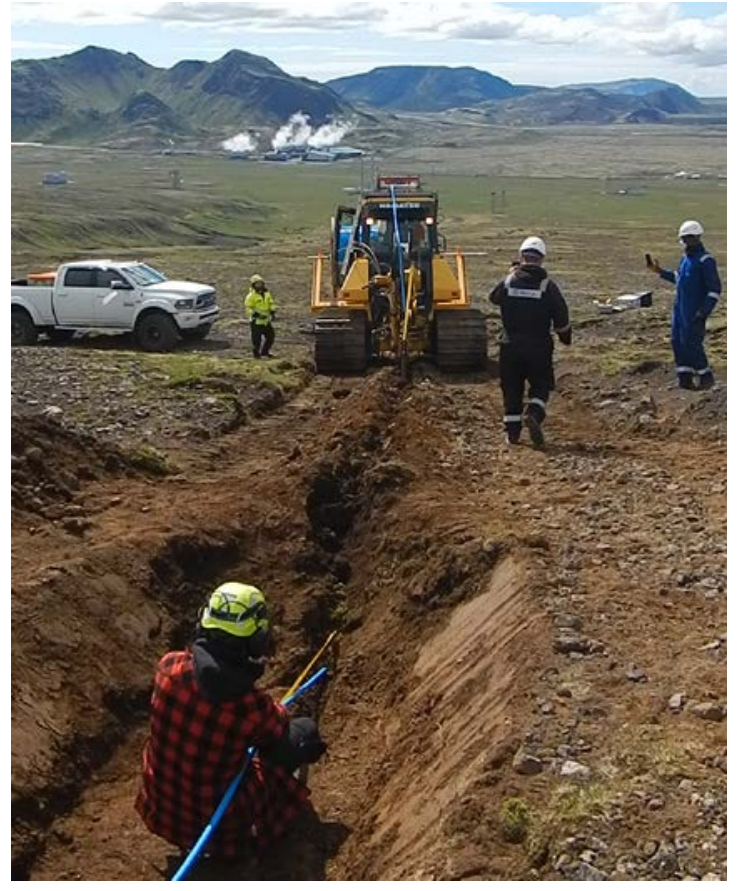

(b) (b)

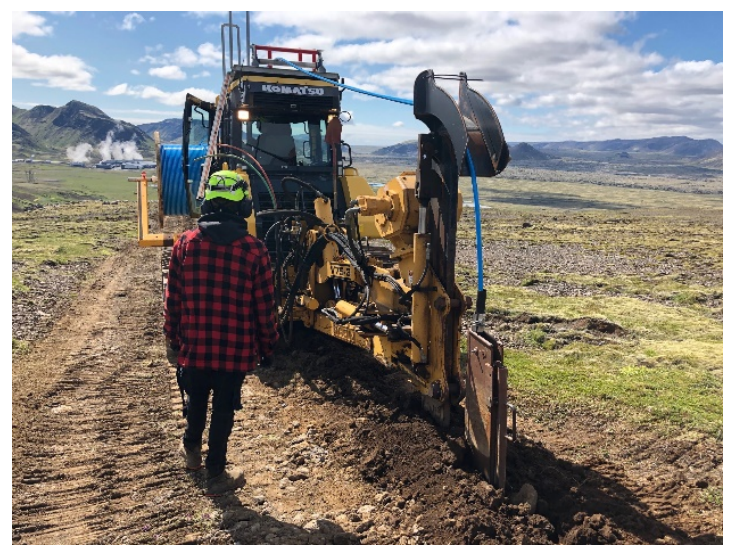

(c) (C)(d)

FIGURE 4: (a) Location of wells at the Hellisheidi site. $\mathrm{HN}-16$ is the $\mathrm{CO}_{2}$ injection well. The blue line is the helically wound cable deployment and the black line is the tactical cable joining the HWC to the DAS interrogator, (b), (c), (d) installation of the HWC at the Hellisheidi geothermal site.

The deployment at the Kizildere site is more complex for several reasons. First, cables will be deployed on the surface in a trench and downhole with HWC on the surface and Constellation fibre downhole in two wells (Figure 5). The temperatures in the boreholes are expected to reach up to $245^{\circ} \mathrm{C}$ and 
therefore cables with a polyimide coating are to be used to prevent heat damage. Passive and active seismic surveys will be conducted to assess the effectiveness and validate the use of fibre-optic monitoring techniques for carbonate reservoirs.

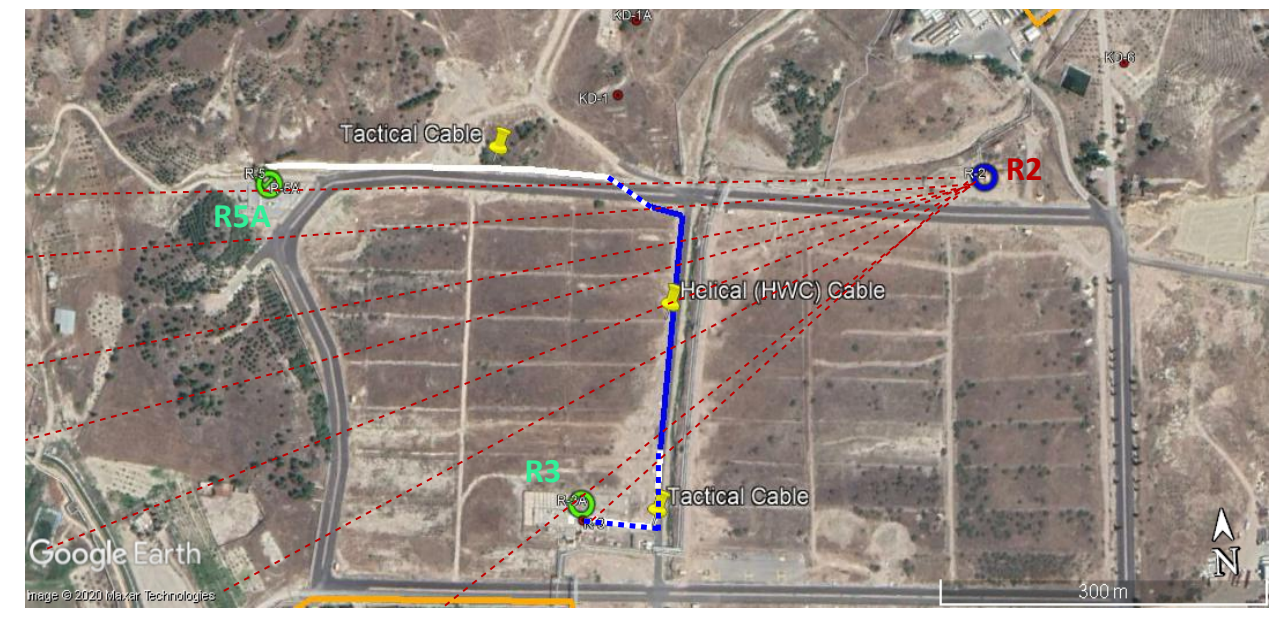

(a)

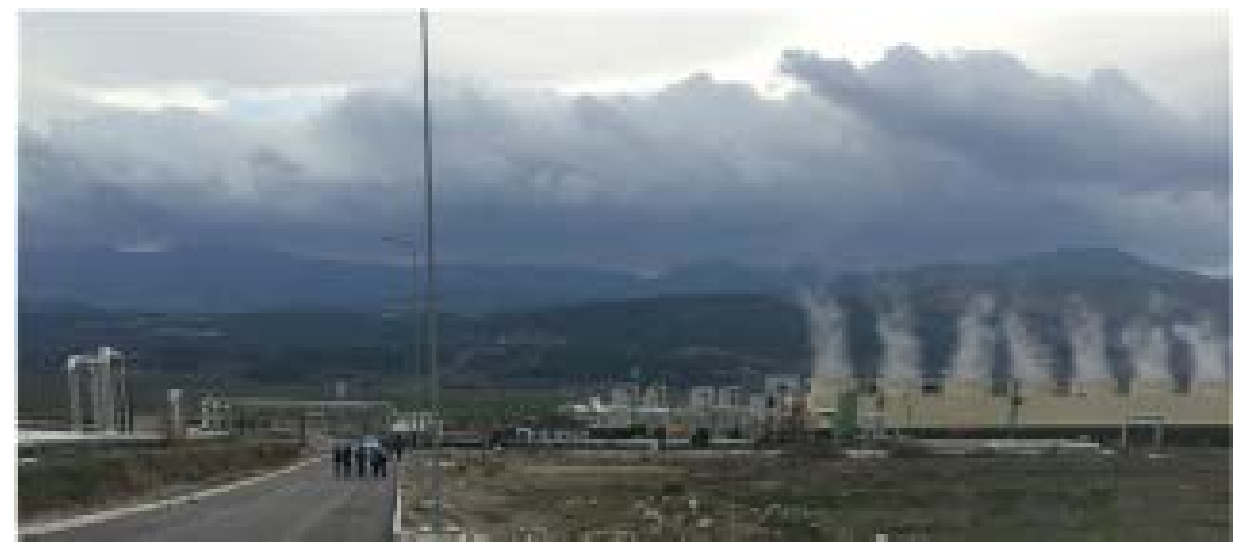

(b)

FIGURE 5: (a) Location of the planned $\mathrm{CO}_{2}$ injection well $\mathrm{R} 2$ and the two monitoring wells $\mathrm{R} 3$ and R5A where the downhole Constellation fibre will be installed at the Zorlu Enerji Kızıldere geothermal field. The blue line is the HWC deployment and the white line is the tactical cable joining the two downhole cables and the HWC to the DAS interrogator. The red dashed lines indicate the tracer flowpaths from previous tests at the site, (b) image of the HWC installation site from the North towards the monitoring well R3 and the Zorlu Enerji Kızıldere-II geothermal power plant.

\section{Fibre-optic monitoring applications}

The applications of DAS monitoring to be tested at the two sites are:

1. Passive seismic monitoring for natural or induced seismicity;

2. Seismic imaging using a new electric active seismic source and ambient noise recordings.

Monitoring the fate of injected $\mathrm{CO}_{2}$ is an important part of project safety and modelling and verification for $\mathrm{CCS}$ projects. Often the main method to track $\mathrm{CO}_{2}$ migration is seismic surveys with 
changes in the seismic response used to determine the extent of the $\mathrm{CO}_{2}$ plume, e.g. in the Sleipner field, Norway (Chadwick et al., 2009). The deployments at Hellisheidi and Kizildere address current limitations for seismic sensing, i.e. limited spatial sampling and narrow spectrum seismic sources, with novel technologies to assess imaging capabilities in carbonate and volcanic settings.

Dense sensor networks are required to produce high-resolution seismic images of the subsurface and sensor spacing is often a limiting factor in migration or full-waveform inversion techniques. The sensors may be deployed at the surface and/or in boreholes. DAS fulfils the requirement for dense spatial sampling and provides the ideal solution for time-lapse surveys with cables buried or cemented permanently in place, attached to tubing or clamped in place. Recent improvements in interrogator and cable technology have increased signal strengths so DAS rivals geophones for use in seismic surveys, particularly for downhole Vertical Seismic Profiles (VSPs) (e.g. Correa et al., 2019).

For active surveys it is challenging to produce a seismic source that is repeatable and emits a broad range of frequencies, particularly the low frequencies required for full-waveform inversion. A newly developed Seismic Mechatronics electric seismic source will be used as the source for DAS data acquisition to test the combined technology potential for imaging the reservoir. The signal is generated at high force with good repeatability due to its frictionless design (Noorlandt et al., 2015). At Kizildere, where cable is to be deployed in two wells, active seismic data will be used to conduct time-lapse VSPs and tomography studies. A baseline survey before injection will provide a calibration dataset to enable the effects of injection to be observed.

Another challenge for high-resolution imaging and monitoring is understanding the propagation of the seismic signals through near-surface layers. If there is high lateral heterogeneity in these layers, defocusing at the required target depth could result in a poor description of the seismic velocities which are, in turn, required for accurate migration and inversion. Thus, substantial efforts are made to correctly assess near-surface geology (e.g., Place and Malehmir, 2016; Bakulin et al., 2017). Seismic interferometry can be used to determine these effects and Bakulin and Celvert (2006) proposed redatuming to borehole receivers placed below the near-surface layers. The method proposed here, goes further as it uses interferometry methods withsources and receivers at the surface and still provides layer-specific information about specific targets in the subsurface, e.g., the reservoir or an overburden layer.

The information from the active and ambient noise surveys will provide important layer-specific monitoring of subsurface changes at regular intervals and relate them to $\mathrm{CO}_{2}$-enhanced geothermal production. The Hellisheidi field, being a relatively mature injection site, also provides the project with the opportunity to characterise the altered bedrock and its petrophysical properties to provide more accurate estimates of storage capacity.

Microseismic monitoring of $\mathrm{CO}_{2}$ injection projects helps highlight active fractures and faults, potential leakage pathways for dissolved or supercritical $\mathrm{CO}_{2}$. Fractures may be naturally active or activated by an increase in pore pressure or through an increase loading on a fault due to stress changes caused by injection (Ellsworth, 2013). If hydraulic fracturing of the reservoir occurs this creates new fractures, also potential leakage pathways. Monitoring microseismicity is therefore an important aspect to understand and verify the geomechanical response of the reservoir. Downhole microseismic monitoring is a common application of DAS in, for example, the hydraulic fracturing industry and it has also been implemented at enhanced geothermal (EGS) sites (Mondanos and Coleman, 2019). However, surface monitoring with the technology is not common because a linear cable is unresponsive to vertically propagating P-waves incident on a surface cable. Here, a HWC is tested for microseismic event detection capabilities. A regional seismic network is available for comparison at the Hellisheidi site and at the Kizildere site the surface HWC will be compared with the downhole fibre 
deployments. Initial test data collection from the Hellisheidi site shows clear recordings of regional natural seismicity on the surface cable (Figure 6).

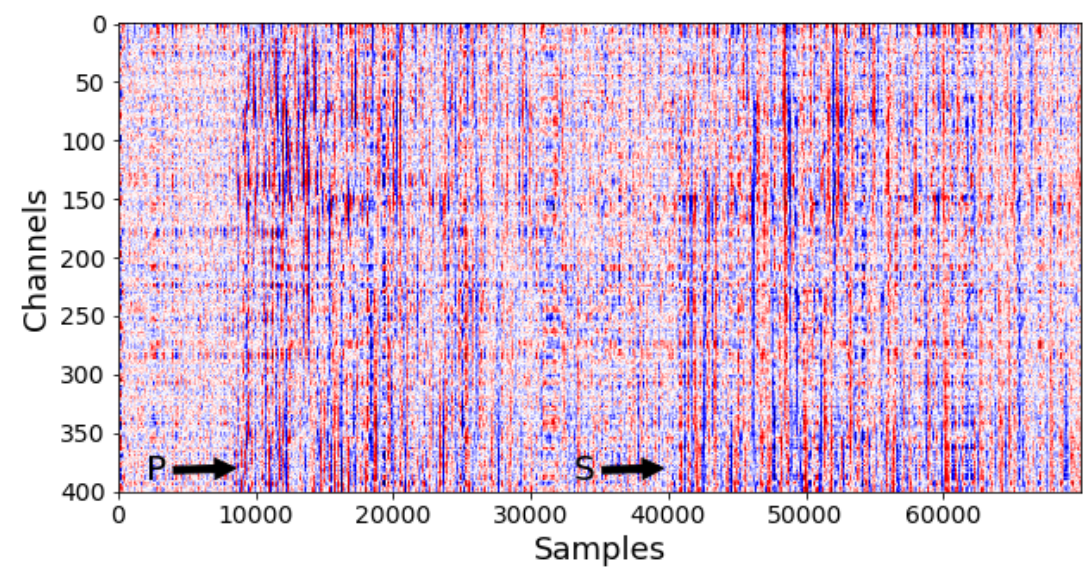

FIGURE 6: A recording on the surface HWC of a M3.3 earthquake on 23 July 2020 with an epicentre approximately $100 \mathrm{~km}$ from the Hellisheidi power plant. The time of P- and S-wave arrivals are indicated.

The installation of cables provides the capability for continuous or semi-continuous monitoring and the aim at the two sites is to determine the correlation between microseismic event characteristics (spatial, temporal and magnitude information) and fluid/ $\mathrm{CO}_{2}$ injection rates. If focal mechanism solutions can be determined for microseismicity it will aid construction of a discrete fracture network to help evaluate the reservoir response to fluid/ $\mathrm{CO}_{2}$ injection.

Seismic monitoring of the geothermal production and $\mathrm{CO}_{2}$ injection processes with the application of innovative technologies will be supplemented with routine conventional monitoring of downhole pressures and temperatures, fluid sampling and tracer breakthrough studies.

\section{Conclusions}

To mitigate the effects of anthropogenic climate change, efforts to develop alternative energy sources are increasing. Geothermal energy has significant potential in many countries, but geothermal environments provide significant technical challenges (high temperatures and harsh conditions) for monitoring. Monitoring CCS efforts in such settings therefore requires specialised equipment. Fibreoptic cable solutions are ideal for geothermal sites up to $300^{\circ} \mathrm{C}$ with dense spatial data sampling, the option of a permanent installation and the possibility for remote operation.

Fibre-optic monitoring has not previously been deployed to monitor $\mathrm{CO}_{2}$ injection in geothermal environments. The geophysical monitoring surveys in the Hellisheidi and Kizildere geothermal fields, in Iceland and Turkey respectively, will evaluate monitoring techniques for $\mathrm{CO}_{2}$ injection in both volcanic and carbonate geothermal reservoirs. In particular the potential of DAS with fibre-optic HWC will be evaluated for use in surface seismic surveys and microseismicity recorded on Constellation fibre in wells and $\mathrm{HWC}$ will be analysed to help understand the effects of $\mathrm{CO}_{2}$ injection. Preliminary data show the fibre-optic array at the Hellisheidi site clearly records regional seismicity. The combination of a new broad frequency band electric seismic source and DAS for monitoring the geothermal reservoir will be tested and the survey at the Kizildere site will provide a baseline for time- 
lapse comparisons. Development of these monitoring capabilities will facilitate up-take of combined geothermal and CCS projects.

\section{Acknowledgements}

SUCCEED is funded through the ACT programme (Accelerating CCS Technologies, Horizon 2020 Project No 294766). Financial contributions made by the Department for Business, Energy \& Industrial Strategy UK, the Rijksdienst voor Ondernemend Nederland, the Scientific and Technological Research Council of Turkey are gratefully acknowledged. We also thank our research partners Orkuveita Reykjavíkur Iceland, Zorlu Enerji Elektrik Üretim A.S. Turkey, Seismic Mechatronics BV the Netherlands, Istituto Nazionale di Oceanografia e di Geofisica Sperimentale Italy, Delft University of Technology the Netherlands and Middle East Technical University Turkey for their contributions to the SUCCEED project.

\section{References}

Baird, A.F. [2020] Modelling the response of helically wound DAS cables to microseismic arrivals, First EAGE Workshop on Fibre Optic Sensing, 2020, 1-5.

Bakulin, A., Golikov, P., Smith, R., Erickson, K., Silvestrov, I., and Al-Ali, M. [2017] Smart DAS upholes for simultaneous land near-surface characterization and subsurface imaging, The Leading Edge, 36, 1001-1008.

Bakulin, A. and Calvert, R. [2006] The virtual source method: theory and case study, Geophysics, 71, SI139-SI150.

Chadwick R.A., Noy, D., Arts, R., and Eiken, O. [2009]. Latest time-lapse seismic data from Sleipner yield new insights into CO2 plume development, Energy Procedia, 1, 2103-2110.

Correa, J., Pevzner, R., Bona, A., Tertyshnikov, K. , Freifeld, B., Robertson, M. and Daley, T. [2019] 3D vertical seismic profile acquired with distributed acoustic sensing on tubing installation: A case study from the CO2CRC Otway Project, Interpretation, 7, SA11-SA19.

Holm, A., Jennejohn, D. and Blodgett, L. [2012] Geothermal energy and greenhouse gas emissions, Washington DC: Geothermal Energy Association.

Humphries, M., Marin Vidal, J.A. and de Dios, J.C. [2016] VSP monitoring for CO2 migration tracking in fractured rock massifs, 78th EAGE Conference and Exhibition, Extended Abstracts, 2016, 1-5.

Karrenbach, M., Cole, S., Ridge, A., Boone, K., Kahn, D., Rich, J., Silver, K., and Langton, D. [2019] Fiber-optic distributed acoustic sensing of microseismicity, strain and temperature during hydraulic fracturing, Geophysics, 84, D11-D23.

Noorlandt, R., Drijkoningen, G., Dam,s J., and Jenneskens, R. [2015] A seismic vertical vibrator driven by linear synchronous motors. Geophysics, 80, EN57-EN67.

Mondanos, M. and Coleman, T. [2019] Application of distributed fibre-optic sensing to geothermal, First Break, 37, 51-56. 
Naldrett, G., Parker, T., Shatalin, S., Mondanos, M. and Farhadiroushan, M. [2020] High-resolution Carina distributed acoustic fibre-optic sensor for permanent reservoir monitoring and extending the reach into subsea fields, First Break, 38, $71-76$.

Obermann, A., Sánchez-Pastor, P., Duran, A., Diehl, T., Hjörleifsdóttir, V. and Wiemer, S. [2020] COSEISMIQ: First results of high resolution imaging of the shallow crust and relocation of induced seismicity in the Hengill area, Iceland, 22nd EGU General Assembly, 4-8 May, 2020, id.12923.

Parker, T., Shatalin, S., and Farhadiroushan, M. [2014] Distributed Acoustic Sensing - A new tool for seismic applications, First Break, 32, 61-69.

Place, J., and Malehmir, A. [2016] Using supervirtual first arrivals in controlled-source hardrock seismic imaging -well worth the effort, Geophysical J. International, 206, 716-730.

Pruess, K. [2006] Enhanced Geothermal Systems (EGS) using CO2 as Working Fluid-A Novel Approach for Generating Renewable Energy with Simultaneous Sequestration of Carbon. Geothermics, 35, 351367.

Richter P., Parker, T., Woerpel, C., Wu, Y., Rufino, R., and Farhadiroushan M. [2019] Hydraulic fracture monitoring and optimization in unconventional completions using a high-resolution engineered fibreoptic Distributed Acoustic Sensor, First Break, 37, 63-68.

Salimi, H. and Wolf, K-H. [2012]. Integration of Heat-Energy Recovery and Carbon Sequestration. International Journal of Greenhouse Gas Control 6, 56-68.

Snæbjörnsdóttir, S.Ó., Oelkers, E.H., Mesfin, K., Aradóttir ,E.S., Dideriksen, K., Gunnarsson, I., Gunnlaugsson, E., Matter, J.M., Stute, M., and Gislason, S.R. [2017]. The chemistry and saturation states of subsurface fluids during the in situ mineralisation of $\mathrm{CO} 2$ and $\mathrm{H} 2 \mathrm{~S}$ at the CarbFix site in SWIceland, Int. J. Greenhouse Gas Control, 58, 87-102.

Snæbjörnsdóttir, S.Ó., Tómasdóttir, S., Sigfusson, B., Aradóttir, E.S., Gunnarsson, G., Niemi, A., Basirat, F., Dessirier, B., Gislason, S.R., Oelkers, E.H. and Franzson, H. [2018] The geology and hydrology of the CarbFix2 site, SW-Iceland, Energy Procedia, 146, 146-157.

Yucetas, I., Ergiçay, N., and Akın, S. [2018] Carbon Dioxide Injection Field Pilot in Umurlu Geothermal Field, Turkey. GRC Transactions, 42. 